\title{
User Perceptions of Powered Wheelchair Features
}

\author{
Dan Bowers ${ }^{1}$, Katie Morgan ${ }^{2}$, Leigh R. Abbott' ${ }^{1}$, Lucy Fishleigh ${ }^{1}$, Alecia L. Cousins ${ }^{1}$, and Rachel Taylor ${ }^{1}$ \\ ${ }^{1}$ School of Psychology and Therapeutic Studies, University of South Wales \\ ${ }^{2}$ South Wales Posture \& Mobility Service, National Health Service Wales, Cardiff, United Kingdom
}

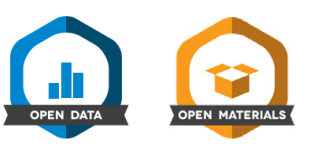

\begin{abstract}
There has been a substantial increase in recent years in the availability of powered wheelchairs and associated features. However, the psychological factors explaining feature use are poorly understood. The current study aims to explore this issue. Semistructured interviews of 15 British wheelchairs users were conducted; all had a range of disabilities and clinically prescribed seating functions. Our aim was to explore participants' perceptions in terms of engagement and use of their wheelchair technology. Interview schedules were generated based on prior research on psychological factors associated with health and well-being. Questions focused on participants' knowledge of features and how to use them, perceived barriers and facilitating factors, motivation to use, and perceptions of social support. A theory led thematic analysis identified three themes: (a) clinical benefits and functional alternatives, (b) expectations versus reality, and (c) the impact of other people. There was diversity in the perceptions that users had of their equipment, with positive views of features linking to users' experience of functional benefits and matches between equipment and prior expectations. Recommendations are made to highlight functional as well as clinical benefits, to explore therapists' experiences of their practice, to consider how information could be presented, and to explore uses of social support and innovative technologies in future work.
\end{abstract}

Keywords: psychology, wheelchair, clinical, engagement, assistive technology

Supplemental materials: https://doi.org/10.1037/tmb0000011\#supplemental-materials

Action Editor: Danielle S. McNamara was the action editor for this article. ORCID iDs: Katie Morgan (D) https://orcid.org/0000-0002-4158-6648; Leigh R. Abbott (D) https://orcid.org/0000-0001-8604-0123; Alecia L. Cousins (iD https://orcid.org/0000-0001-8591-2508; Rachel Taylor (i) https://orcid.org/0000-0001-9285-5337.

Changes of Affiliation: Katie Morgan is now working at Public Health Wales and Alecia L. Cousins is currently a tutor in psychology at Swansea University.

Disclosure and Acknowledgments: We have no known conflict of interest to disclose. This study was funded by South Wales Posture and Mobility Service.

Open Science Disclosures:

In The data are available at https://osf.io/3s $7 \mathrm{nb} /$

The experiment materials are available at https://osf.io/3s $7 \mathrm{nb} /$

Open Access License: This work is licensed under a Creative Commons Attribution-NonCommercial-NoDerivatives 4.0 International License (CC-BYNC-ND). This license permits copying and redistributing the work in any medium or format for noncommercial use provided the original authors and source are credited and a link to the license is included in attribution. No derivative works are permitted under this license.

Disclaimer: Interactive content is included in the online version of this article.

Contact Information: Correspondence concerning this article should be addressed to Dan Bowers, School of Psychology and Therapeutic Studies, University of South Wales, Treforest, CF37 1DL, United Kingdom. Email: dan.bowers@southwales.ac.uk
Over the last 3 decades, the use of wheelchairs within the U.K. has significantly increased. In 1989, the Office of Population Census and Surveys (OPCS) identified the figure of wheelchairs users at 3,60,000 people (Office of Population Census and Surveys, 1989). Thirty years later, the National Wheelchair Data Collection for the U.K. estimates 1.2 million wheelchair users (GOV.UK., 2019), with Wales having the highest percentage of those with disabilities $(26 \%)$ compared to the rest of the U.K. (Papworth Trust, 2018). Further, it is reasonable to assume these figures now include a greater proportion of powered chair users given developments in available technology and following the government's initial funding, specifically for electrically powered chairs in 1996 (NHS Executive, 1996).

Along with this increase in overall wheelchair use, there has also been an evident increase in the provision of powered mobility with seating functions within the National Health Service (NHS). For example, in 2007, the South Wales Posture and Mobility Service issued 179 powered wheelchairs with one, two, or three seating functions. By 2017, this figure had increased $256 \%$ to 638 powered wheelchairs issued. These built-in technological features, also known as assistive technology (e.g., tilt-in-space, recline, and elevating leg rests), are for those who are powered wheelchair users and are specifically prescribed by clinicians to align posture, prevent contractures, and to reduce the risk of pressure ulcers; the approximate cost of these seating functions ranges between $£ 200$ and $£ 1,000$ per wheelchair. 
What is evident from the above is that there are clear increases in the use and provision of equipment to support those with posture and mobility issues. Furthermore, innovations in the technology and design of features are occurring continually. Examining manufacturer websites and product lists or attending professional conventions and trade fairs reveals a comprehensive and wide-ranging array of equipment suitable for fitting to power chairs as well as developments in the chairs themselves. This provides an increased number of power chair options for a clinician or a private purchaser and the range and functionality of features fitted to chairs can only improve with further advances in design and manufacture.

Given the increasing importance of power chairs and their associated functions to users with posture and mobility issues, the current study explored literature surrounding powered wheelchair user's perceptions of their built-in technological features.

From the perspective of ergonomics, there are established literatures on chair design and universal design of human-computer interaction (e.g., Helander, 2003; Smith \& Salvendy, 2001). In addition, there is some research on manual wheelchair users' engagement in pressure-relieving movements (e.g., Stockton \& Parker, 2002), and some on psychological factors relating to "wheelchair use confidence" (e.g., Sakakibara et al., 2015). Further research did identify several relevant topics associated with both powered and manual wheelchair use. For example, a substantial amount of research was found relating to self-efficacy and social support in manual wheelchair athletes and those actively part of a disability sport (e.g., Anderson et al., 2008; Fliess-Douer et al., 2013; Greenwood et al., 1990; Martin, 2002, 2008; Martin \& Mushett, 1996). Research also indicated the presence of environmental constraints restricting participation in society; for example, manual wheelchair users in India being unable to participate in outdoor activities due to transportation barriers (Devi et al., 2013), and manual and powered wheelchair users reducing their community participation during the winter months in Canada (Ripat et al., 2015). Extensive research into assistive technology and augmentative and alternative communication modalities for those with intellectual and developmental disabilities was identified (see review by Sigafoos et al., 2016; Stasolla et al., 2016). Additionally, research that has measured the length of time a powered chair user engages and utilizes their seating functions (i.e., tiltin-space, backrest recline, and seat elevation) is also reviewed (Ding et al., 2008). Specifically, Ding and colleagues (2008) saw that powered wheelchair users' usage of seating functions varied, with very little time spent in a fully upright position.

However, the review of the extant literature above indicated a lack of powered wheelchair-specific research on psychological factors that might explain different types of use. Moreover, there seems to be a lack of literature on the powered wheelchair user's perceptions of their primary assistive technology. Thus, we decided to investigate literature aligning to this paucity of research.

\section{Literature Review}

\section{Psychological Concepts of Technology Use}

The patient using a brain-computer interface to control a wheelchair will not typically know just how it all works or be able to reconfigure the interface or software at will. But in this respect too, the new equipment is simply on a par with much of the old. To fear that this must inevitably lead to dilutions of self-control and diminishment of responsibility is to miss the fact that we are already host to scores of similarly hidden processes. (Clark, 2007, p. 279)

Cognitive psychology has thoroughly explored perceptions of human-technology interaction; ranging from research defining perceptual engagement (O'Regan \& Noë, 2001) through to work on embodiment (Varela et al., 2016) and grounded cognition (Black, 2010). Clark (2007) proposes that the key for technology advancement, such as primary assistive technology, is to have a goal-driven motor engagement derived from profound embodiment. Consensus definition of embodiment is that it is the state of the body in terms of posture, limb movements, facial expressions that arise from social interaction, be that a person or an organism, as a result of sensorymotor activity (Barsalou et al., 2003; Smith, 2005). An extension of embodiment to profound embodiment is when a person actively engages in their surroundings to the extent that they can "use" their own body within the environment (Clark, 2007). For example, Schrope (2001) examined U.S. Navy personnel wearing a tactile flight suit that indicated when a craft isoff-balance. The signaling of tilt motion would blow a puff of air into the suit where the craft is offbalance. Thus, if the craft tilted to the right, the personnel would feel the air in the right side of their body. Movements from the U.S. Navy personnel to the opposite direction of the tilt from the craft would restore the craft's balance. The personnel were said to be able to complete this blindfold and saw this as an extension of their body. For power chair users, the chair features may facilitate profound embodiment as this involves a way of allowing this active engagement with the environment.

Grounded cognition specifies the body's role within cognition. In relation to those who are wheelchair users, it can be as follows: (a) easing into a chair, the brain/mind gains information on the modalities and connects it to a multimodal representation that has been stored within memory, thus, what the chair looks and feels like, comfort associated to it, and how to use; (b) knowledge of the chair to then categorize it; and (c) multimodal representations from experiences simulate how the brain/mind associates the chair in relation to action, perception, and introspection (Barsalou, 2008). Therefore, grounded cognition could help to shape a wheelchair user's wider experiences.

Although the cognitive science literature explains the brain's process in understanding an interaction with technology, it does not specify why someone might engage with and adhere to technological devices. Thus, a further examination of the literature was undertaken.

Psychological research about the decision to, and frequency of, the use of inanimate objects has found that users (and those who are significant to them) connect to the inanimate object if they have a positive attitude towards it (e.g., the use of a microswitch technology to present independent leisure and communication engagement for those with multiple disabilities; Lancioni et al., 2017). Additionally, both intention and actual use relate to the user's understanding of the object (e.g., predicting the use of fitness trackers for wheelchair athletes; Carrington et al., 2015). Direct previous experience is helpful for establishing stronger positive evaluations, although evaluations can be established through indirect exposure as well (see Ledgerwood et al., 2018 review). Acquiring a habit can predict the future or continued use (e.g., using a wheelchair fitness tracking device for improving skills in wheelchair basketball; Carrington et al., 2018). This can create expectancies about the efficacy of the object; and these can directly contribute to the user developing a sense of self-efficacy 
(Bandura \& Adams, 1977), which itself can be predictive of behavior (Carvalho et al., 2015). Finally, the type and frequency of using an object can be affected by the goal that the user has in a certain situation (Lin, 2011), as well as by idiosyncratic features of the context itself, for example, microswitches for those with multiple disabilities and limited physical movement (Lancioni et al., 2010, 2011; Stasolla \& De Pace, 2014).

Although social scientists have taken an integrated position in the analysis of technology (e.g., Dourish, 2004; Heath \& Luff, 2000; Heath et al., 2003; Suchman \& Suchman, 2007), the wheelchair offers an interesting perspective on movement in space integrating both cognitive and social aspects of powered wheelchair user's perceptions of their primary assistive technology. However, for these cognitive processes to occur, the process of how power chair users engage with their assistive technology needs to be better understood. Therefore, to understand the use and perceptions of assistive technology, social psychological theories in relation to health behavior were explored.

\section{Theory of Planned Behavior and Health Belief Model}

A review of social psychological theories was conducted, and two main ones emerged as relevant: The theory of planned behavior (TPB; Ajzen, 1991) and the health belief model (HBM; Rosenstock, 1974).

The TPB focuses on the role of expectancies and outcomes (predicting attitudes), other people's perceptions, and perceptions of one's own ability to complete a behavior. The HBM addresses barriers and facilitating factors that predict engagement in certain health behaviors. This model draws on the perception of risk, barriers, and the severity of illness in terms of engaging in a health promotion type of behavior. These perceptions fall into several categories including structural (e.g., funding for an assistive technological feature that a user deems as necessary), cognitive (e.g., understanding on the importance of using features), situational (e.g., time within an employment setting to commit oneself in pressure-relieving movements through a tilt-in-space feature), and biological (e.g., engagement and action in pressure-relieving assistive technology).

Although both models have been useful and influential (see Sheeran et al., 2017 for a review of health behavior change models), the lack of literature specifically on power chair users meant that a single theoretical perspective could not be applied. It was unclear whether users' accounts of how and why they used their features in specific contexts would map to a single theoretical approach; therefore, a model in relation to technology use was explored as a potential framework for this study.

\section{Technology Acceptance Model}

One psychological perspective applicable in the current context is the technology acceptance model (TAM; Yoo et al., 2012). This argues that intentions to accept/reject new technologies predict actual decisions. The user having a positive attitude towards the technology and a positive perception of its utility, in turn, predicts this intention. Perceived utility also indirectly predicts intention by affecting attitude, while attitude is further predicted by perceived ease of using the technology. External factors/variables (such as the user interface) predict perceived utility and perceived ease of use. This model has been applied extensively to different technologies, from social media use (Dumpit \& Fernandez, 2017) to the use of wearable healthcare devices (Park et al., 2016) to computerized 3D interior design applications for community dwelling older adults to decide on their home adaptation process (Money et al., 2015). This suggests that the TAM has the potential to explain engagement with technology by groups who may find their participation in society is restricted by environmental constraints. As discussed earlier, this may relate to wheelchair users.

The TPB has also been integrated with the TAM in other domains of healthcare technology. For example, Lunney et al. (2016) have integrated elements of the TPB such as descriptive and injunctive norms into a version of the TAM applied to the use of wearable fitness trackers. Additionally, although the TAM does not explicitly integrate with the HBM, the idea of perceived ease of use and perceived utility as barriers (if seen negatively) or facilitating factors (if appraised positively) would fit directly with the HBM. This indicated that the TPB, HBM, and TAM were useful theories to apply to the context of understanding powered chair users' perceptions of their prescribed assistive technological features.

\section{Rationale for This Research}

These studies identify that not only can the use of technology influence psychological processes but also that psychological factors can affect the decisions to use specific forms of technology. Further, this research identifies these relationships may be affected by other factors, and thus, knowledge of the range of psychological processes is necessary to fully appreciate these effects. As research on psychological aspects of power chair use is so limited, this provided us with a rationale to assess power chair user's perceptions of utilizing their assistive technological features. Moreover, gathering information from powered wheelchair users themselves may provide researchers with insight from a direct source on user's perception and usage of assistive technology. Therefore, the current study aimed to address this by conducting an exploratory qualitative investigation.

Due to the lack of research in powered wheelchair user's engagement, use, and perceptions of their prescribed technological features, we thought it necessary to address this gap; (a) to understand the user's experience of their own technological features that are the primary mode of their mobility and (b) for clinicians to understand powered chair users' perceptions of their assistive technology and how this contributes to engagement with clinical recommendations.

\section{Research Question}

As this was a qualitative exploratory study and novel in this specific area of research, no specific predictions were made. However, the study aimed to have rich interviews with those who have direct use of the assistive technology to address the research question of: How can psychological features, concepts, or processes derived from theoretical approaches such as the TAM, TPB, and the HBM be used to understand powered wheelchair users' perceptions and the use of their assistive technological features?

On this basis, no clinicians, family members, or caretakers were interviewed for this study.

\section{Method}

\section{Methodological Orientation}

To understand powered wheelchair users' perceptions and experiences of the features of their chairs, the study adopted a 
phenomenological approach within an interpretivist paradigm through semistructured interviews. As the study was concerned with perceptions and evaluations rather than lived experience, a theoretical latent thematic analysis was used as an analytic method. The study followed accepted guidelines for reporting qualitative research, specifically the considered criteria for reporting qualitative research (Tong et al., 2007).

\section{Research Team and Reflexivity}

The third author conducted all interviews. This author had prior experience of conducting research interviews, had already obtained both Bachelor's and Master's qualifications in Psychology, including a Masters of Research in Psychology specifically exploring rehabilitation methods for disabled individuals, and had extensive experience of working in paid and voluntary roles with individuals with disabilities (including wheelchair users). The interviewer had no prior connections with any of the research participants, however, had some prior connections to charitable and support organizations from whom participants were recruited; having volunteered in these settings. Topics for the interview were generated by three of the six authors based on their experience with social psychological literature (authors one, three, and six) and prescription of power chair features (author two). The first and final authors also provided training and practice opportunities prior to the interviews being conducted.

\section{Participant Selection and Setting}

A convenience sample of participants was obtained for the study. This comprised of 15 participants (7 males and 8 females; mean age $=54$ years and $S D$ of age $=18.17$ ). Inclusion criteria were that all had to be users of powered wheelchairs with a range of clinically prescribed assistive technology/seating functions, and all had the capacity to consent to participation. No restrictions were placed on the age and gender of the participants, nor on the condition that underpinned their powered chair use. All interviewees were from the U.K. (14 Welsh, 1 English: 14 White British, 1 Black British) to gain some consistency of the prescription and funding experience and all had features prescribed through the NHS. No information on socioeconomic status or sexual orientation was required for this research.

Participants were recruited through charitable organizations, support groups, and from advertisements presented at the University of South Wales campus. As recruitment was through interested participants contacting the third author, the level of nonparticipation is impossible to determine; however, all participants who made initial contact then provided interview data. Participants were interviewed face-to-face $(N=9)$ or via video call (Skype, $N=6$ ) depending on the participant's preference and their geographical proximity to the research facility. Although the study was conducted on participants who had capacity to consent, some interviewees preferred to have a caretaker or family member accompany them.

Features of the participants' assistive technology were recorded. This included pressure cushion (86.67\%); tilt-in-space $(53.33 \%)$; elevating leg rests $(46.67 \%)$; recline $(73.33 \%)$; headrest $(73.33 \%)$; curb-climber (33.33\%); pelvic belt $(66.67 \%)$; riser (13.33\%); lynx backrest, chest harness, shoulder harness, and heel loops (6.67\%); lateral thoracic supports (40\%); hip guides (13.33\%); knee blocks (20\%); pommel (20\%); and due to have features (such as leg rests and tilt: $6.67 \%$ ). For further details, please see Table A1 in the Appendix.

\section{Data Collection}

A broad list of topics was generated, reviewed, and refined by the research team through discussion. Additionally, the second author discussed the topics with colleagues in her service to review and refine further. Finally, these were mapped to social psychological perspectives to ensure that topics covered a range of possible psychological factors. Table 1 shows the topics, subtopics, and how this links to psychological theory. These broad topics were used to generate questions to help facilitate a conversation with participants. The process followed the general advice provided by Johnson and Rowlands (2012) for conducting in-depth interviews. Specifically, the interviewer took a flexible approach in which they asked questions in a responsive manner following the flow of the conversation and were mindful of constraints such as participant fatigue. Additionally, participants were able to decline to answer any question or to add other information they felt was relevant or useful for reflecting their experiences.

On being recruited to the study, participants were provided with an information sheet and a copy of the areas for discussion. They were given time to consider whether they wished to continue before being asked to provide informed consent. Participants completed a single interview; these varied in duration from 6 to 62 min depending on the participant (mean $\min =26.33$ and $S D \min =16.42$ ) and were audio recorded using a Sony IC digital voice recorder (Model No: ICDPX312). No additional notes were made during the interviews themselves. Interviews were transferred via USB to an encrypted computer folder and transcribed by the third author on Microsoft Word. Once transcription of the interviews was complete, participants were offered the opportunity to review their transcripts prior to analysis. All data were then made anonymous in accordance to the U.K. General Data Protection Regulation (GDPR; Information Commissioner's Office, 2018). Although the research was conducted on a limited timescale ( 1 day a week over 6 months), the research team reviewed interview transcripts on a rolling basis; it was determined that data saturation had been reached following 15 interviews.

\section{Ethics}

Ethical approval was obtained from the Faculty of Life Sciences and Education Ethics Subgroup at the University of South Wales in 2016 .

\section{Data Analysis}

Following transcription of audio files, the interviews were then analyzed using a theory-led latent thematic analysis. The purpose of adopting a theory led approach was to establish credibility (Shenton, 2004), by assessing congruence with previous research findings using TAM, HBM, and TPB. This approach has been used in previous research exploring experiences of individuals with chronic health conditions such as Crohn's disease (Wilburn et al., 2017). The thematic analysis process followed Braun and Clarke's (2006) recommendations. This involved multiple stages: transcribing and reading the transcripts, noting points of interest (initial coding), generating themes from these points, clustering themes into 
Table 1

Interview Topics, Subtopics, and Links to Theoretical Perspectives

\begin{tabular}{|c|c|c|}
\hline Topic & Subtopics & Links to theoretical perspectives \\
\hline $\begin{array}{l}\text { Demographic information and } \\
\text { rapport building: } \\
\text { background, historical } \\
\text { factors, and usage levels }\end{array}$ & $\begin{array}{l}\text { - Establishing whether the participants condition is } \\
\text { congenital or acquired } \\
\text { - Determine whether the participant attended } \\
\text { special educational needs or mainstream school } \\
\text { - The rate at which they use their wheelchair } \\
\text { features }\end{array}$ & $\begin{array}{l}\text { N/A: Designed to elicit biographical information and } \\
\text { build rapport }\end{array}$ \\
\hline $\begin{array}{l}\text { Knowledge of the feature and } \\
\text { how to use them }\end{array}$ & $\begin{array}{l}\text { - Their experience of being fitted for their chair: } \\
\text { - The information they received on how to use the } \\
\text { features } \\
\text { - How much they understood this information } \\
\text { - Their confidence in being able to use the features }\end{array}$ & $\begin{array}{l}\text { Technology acceptance model: perceived utility and } \\
\text { perceived ease of use } \\
\text { Health belief model: cognitive barriers/facilitating factors } \\
\text { Theory of planned behavior: attitudes and perceived } \\
\text { behavioral control } \\
\text { Bandura's theory of self-efficacy: the self-belief of } \\
\text { accomplishing a task }\end{array}$ \\
\hline Barriers/facilitators & $\begin{array}{l}\text { Practical barriers and facilitators such as user's like- } \\
\text { lihood of engagement with the wheelchair features in } \\
\text { terms of practicality } \\
\text { - Psychological barriers and facilitators }\end{array}$ & $\begin{array}{l}\text { Technology acceptance model: perceived utility and } \\
\text { perceived ease of use } \\
\text { Health belief model: cognitive barriers/facilitating factors }\end{array}$ \\
\hline $\begin{array}{l}\text { Motivation and understanding } \\
\text { benefits }\end{array}$ & $\begin{array}{l}\text { - Are participants motivated to use the features on their } \\
\text { wheelchairs? why/why not? } \\
\text { - Do they understand the benefits of the features? } \\
\text { - What are their perceptions of the degree to which } \\
\text { other people in chairs also use these features? } \\
\text { does that influence how they think about their } \\
\text { own use? }\end{array}$ & $\begin{array}{l}\text { Health belief model: cognitive barriers/facilitating factors } \\
\text { Theory of planned behavior: attitudes and perceived } \\
\text { behavioral control }\end{array}$ \\
\hline Support & $\begin{array}{l}\text { - Do people spend time accessing support (either } \\
\text { online or face-to-face) from other individuals who } \\
\text { use wheelchairs? } \\
\text { - What type of support? } \\
\text { - How did they initially become involved? } \\
\text { - Benefits of support? }\end{array}$ & $\begin{array}{l}\text { Theory of planned behavior: attitudes and perceived } \\
\text { behavioral control } \\
\text { Lazarus and Folkman's psychological stress and coping } \\
\text { theory: perceived social support }\end{array}$ \\
\hline
\end{tabular}

superordinate categories, and then producing a narrative description of each theme linked to prior literature. Three of the authors (the first, second, and final authors) coded the transcripts and conducted separate thematic analyses; the third author did not code nor conduct thematic analysis to reduce bias of our findings. Due to the small number of transcripts, no coding software was used. This independent researcher triangulation was used as a way of establishing credibility; with consensus on final themes being arrived at by discussion with clear links to research and theory.

\section{Data Availability Statement}

All materials have been made publicly available via Open Science Framework (Open Science Framework, 2020). This includes the following: anonymized descriptive demographic data; anonymized transcripts; analytical methods (R code of Figure 1); and an original blank copy of the information sheet, consent form, participant demographics sheet, and debrief sheet.

\section{Results}

Following a theory led latent thematic analysis, three themes emerged around the central idea of explaining why participants engaged with the features on their chairs (see Figure 1). These were as follows: (a) clinical benefits and functional alternatives, (b) expectations versus reality, and (c) the impact of other people.

\section{Discussion}

\section{Theme 1: Clinical Benefits and Functional Alternatives}

The first theme focused on how participants understood the clinical benefits (e.g., reducing curvature of the spine) of their prescription and the emphasis placed on this compared to functional benefits (e.g., being able to sit and watch television effectively).

It was seen that those with a more positive attitude and intention towards a feature were more likely to understand the outcomes and the associated costs/benefits of these.

Interviewer: What features are you having on your new wheelchair?

Participant L: Oh, I'll have cushions on the back, cushions underneath. It'll be all the mod. It'll be everything Ineed. The legs will go up, the back will go down. It'll be lovely.

Interviewer: And, because you are having these new features, were you told the benefits of each of them? 


\section{Figure 1}

Process and Emergence of Themes Through a Theoretical and Latent Thematic Analysis. Red Outline of Nodes Represents What Themes and Discourse Were Found. Diagram Coded in R by the Third Author

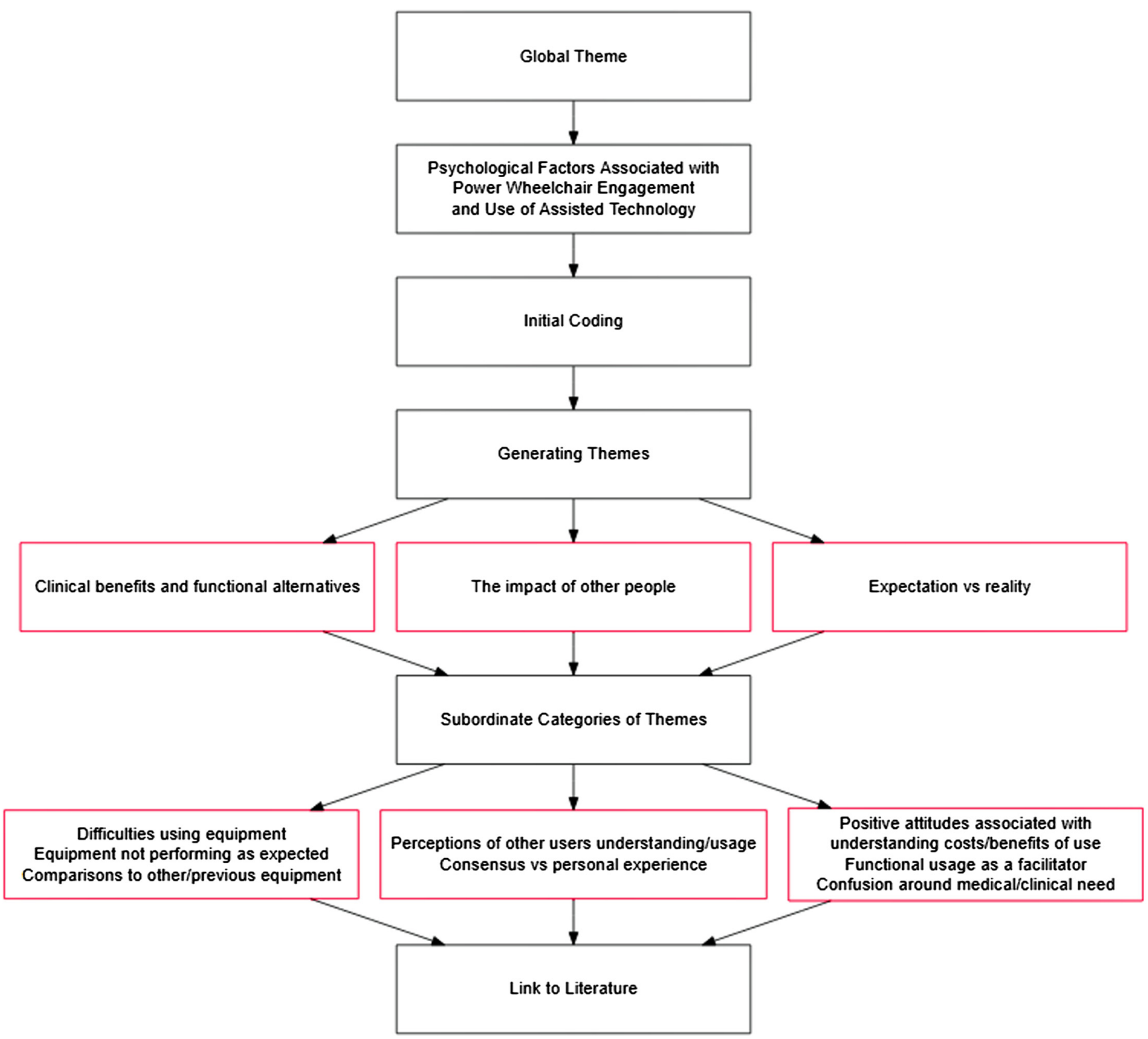

Participant L: I was told, yeah, that it will help me. My back wouldn't curve, because my back is beginning to curve because I am beginning to go to one side. It will help me get me back and... They told me there will be big benefits.

Interviewer: Do you understand the benefits of the different features?

Participant C: Yeah. I've got a bad back. I got a thing put in, I call it "fitted back". A bit like a sport seat like in sports car or something. Hugs you a bit in the seat so that you don't jerk about so much... it comes out a bit so you're in the seat and you can't fall out of it...when you are driving around and worried about falling off the seat... because I've got a very bad back, they fitted and supplied it.

Initially, for $\mathrm{L}$ and $\mathrm{C}$, these benefits seem to be functional. However, as the discussion progresses, both $\mathrm{L}$ and $\mathrm{C}$ describe the benefits in terms of clinical improvements. This fits with the idea of an expectancy that the behavior will produce a positive 
outcome (Ajzen, 1991) and could be considered a facilitating factor in the HBM (Rosenstock, 1974).

Despite this discussion of clinical benefits, L's quote may also reflect a greater priority on functional ones. L was "told" about the clinical benefits and reverts to reproducing what was said at the end of the quote. This fitted with other participant experiences which suggested some did not fully understand the clinical benefits of the features. For Participant M, E, and J, this was associated with some confusion as to why the assistive technology was prescribed and how to best engage with the feature.

Participant M: I understand them. I definitely in all the technical kind of ways so how they fully work and what they are supposed to do ... but maybe there's like a medical side to it that I don't fully understand, for example, the tilt in function is so I can sit in the same position all day and maybe there is some medical side to use on it that I don't know about.

Participant E: ...But yeah never really had any discussion with [hospital name] other than them telling me how it worked really wasn't it? I don't think there was ever a debate about positioning and reposition for posture was there?

Partner of Participant E: No.

Interviewer: $\quad .$. Do you understand why the features are there and what the benefits are?

Participant J: Um. No, Idon't understand, but ... To me it's just el... I call them my electric legs *giggle*

This is consistent with the HBM, where perceptions of barriers and facilitating factors predict engagement in a health behavior. In this case, the lack of understanding could be considered a barrier to engagement. It could also relate to the importance placed by the TAM on perceived utility, in this case, a lack of understanding of the clinical features. In addition, it could reflect differences across participants in health literacy and is supportive of other research where low levels of health literacy have been shown to affect health outcomes (van der Heide et al., 2015).

Tests of health literacy have been developed to assess patients' abilities to comprehend health-related information because of its importance to self-reported health and participation in healthcare systems (van der Heide et al., 2015). As users of powered wheelchairs might vary in age and cognitive ability, individual differences associated with health literacy and healthcare engagement might need to be considered as well as the involvement of family members or caretakers. Research has found that constructing an advertisement based on autobiographical memories influences attentional control and positivity towards using a product (Sanchez \& Alley, 2016), as well as enabling the person to focus attention without distractions (Lavie, 2010). Therefore, it may be necessary for clinicians to consider ways of providing support to users with a variety of individual differences. For example, Participant $\mathrm{R}$ mentions how ability can influence the comprehension of the assistive technology, and Participant $P$ notes that without advice from a clinician, powered chair users may not use the features that are prescribed to them.

Interviewer: $\quad \ldots$ Do you believe that um chair users use all of their functions?

Participant R: $\quad$ No ... Some of them are hopeless ...Q is tremendous in it. But he's been in a wheelchair since birth... So I mean he knows how to drive wheelchairs...God, there are some very low down the other end of the scale... That shouldn't be out. They shouldn't have a wheelchair... I've seen some dangerous ones... Not being able to control it ... I've seen them hitting lampposts ... when they're not looking... So there is lots of different levels of abilities, that's the thing...that's the word I was looking for. The ability to use it.

Interviewer: ...So do you believe that other wheelchair users use all of their functions on their wheelchairs?

Participant P: $\quad$ Uh. I don't think. I think there's quite a few people that don't know that they've got certain features on their wheelchairs that could help them... You don't seem to get much advice from, um, your occupational therapist or your physiotherapist because you're not always seen constantly by them.

Despite this, the need for increasing understanding about clinical benefits did not necessarily mean users did not engage with the features per se. As seen below, users engaged with the features because they had some functional benefit in their everyday life.

Interviewer: Do you understand the benefits of certain features, such as tilt in space?

Participant A: Well yes... we've taken some holidays and instead of going on a recliner or a sunbed, I can just recline the whole seat back... Yeah, so it's good in that respect... When I've been at the dentist, and I couldn't transfer to the seat, he did my crown in the wheelchair, because basically it ends up like a dentist chair when it goes all down flat.

Interviewer: Do you use the elevating leg rests often?

Participant R: Only if we're going... up and down ramps.

Interviewer: Oh, just to lift your... 
Participant R: Yeah, cos you go down the ramp, your legs are down like that *uses hands to demonstrate*, you'll catch on the road.

Interviewer: So, do you know what features are on this wheelchair?

Participant N: There's indicators, hazards and I can have like- if I want to go up to a bar I can higher my chair up.

In the quotes above, Participant A is asked specifically about the benefits of the features and the answer focuses solely on the functional use, while Participant $\mathrm{R}$ applies their leg rests to solve an environmental constraint (the ramp), and Participant $\mathrm{N}$ uses the riser feature for social reasons (to go up to the bar). These quotes would suggest that the functional reasons were enhancing participants' daily living and could again be aligned to the TAM's perceived utility component in the experiences of power chair users. Whilst functional reasons would be a key component of clinical prescription and is positive for users, this alone may not produce clinical benefits. Therefore, it is possible that recognizing functional alternatives as a priority for participants would provide a means of "engaging" them in activities which would be clinically beneficial. This could provide a partial solution to the issues raised by these users. However, it should be emphasized that this might not be enough in all cases. As discussed by Jan et al. (2010), wheelchair users' preferences were for angles of tilt-in-space and recline which were insufficient to reduce the development of pressure ulcers. Therefore, while functional benefits should be part of a discussion to engage users, the clinical benefits should also be emphasized in more detail and reinforced over time by clinicians to ensure that users see outcomes that are beneficial in terms of health.

\section{Theme 2: Expectations Versus Reality}

This theme included several aspects of a participant's experience, all centered around what the person's expectations were of the equipment and how these compared to the reality of usage. The quotes below illustrate different aspects of this experience. For Participant $\mathrm{G}$ and $\mathrm{P}$, the discrepancy is between the expectation of a smooth and responsive tilt-in-space experience and the reality of something which is more difficult to operate.

Participant G: $\quad$ Physically it is a little bit more difficult to tilt it back I guess ... I would like it if it moved a little bit faster because I feel like it tilts really, really, really slow... it seems like you take forever if I have to do anything I have to resituate.

Interviewer: ... So would you say you use the tilt in space and the hoist etc. all the time, or just every now and again?

Participant P: $\quad$ The tilt one is every so often. Because normally I find a comfortable position and try and stick with it . . . because it's a bit of a pain because I've got to get out of the wheelchair and adjust it then get back in, see if it's alright... It can be quite awkward.

While the participants do not express "dissatisfaction" per se, the difference between expectations and reality could be classified as a barrier as discussed in the HBM. Even small barriers such as these could potentially act as deterrents if the behavior needs to be performed frequently. It is unclear from the interviews with these participants whether the expectations came from the initial prescribing process or from other sources. However, the quote from Participant $G$ suggests the experience is comparable to that of a previous chair ("a little bit more difficult"). Prior experience to a situation can affect the way that future situations are approached. This is epitomized in the TPB in how attitudes are formed by expectancies and the values associated with them (Ajzen, 1991). Therefore, being aware of the impact of these past experiences could assist clinicians when prescribing new features to existing users.

As well as the mismatch between expectations and experience, some participants highlighted that the reality of using clinically prescribed features in a nonclinicalway could raise issues. The quote from both Participant $\mathrm{A}$ and $\mathrm{K}$ below illustrates this.

Participant A: Because I'm not using the seatbelt, obviously it would be easier if I used a seatbelt ... The trouble with a seatbelt is, if you haven't got it on, it dangles down the sides... So you have to shorten it and tuck it away in the back. It doesn't make it easy to put on and off easily.

Participant K: $\quad$.. They fetched me down a child's one, they took me around the hospital ... to see if I can handle it, in and out of the thing. Then, they took you out in their car-park thing and they had ramps and how to get up steps and things like that ... it was easy down there. Absolutely easy until we brought it home.

Interviewer: Oh okay. What was wrong with the one you brought home?

Participant K: Well. Where we live, we've got all hills.

It is possible that, for $\mathrm{A}$, the benefits of having the seatbelt fastened sometimes are functional rather than clinical (e.g., to increase a sense of safety and stability when navigating certain terrain). However, the key point for A here is that the costs of having the belt unfastened when it "dangles down the sides" outweigh the benefits of having it attached to the chair. A model developed in the field of human-computer interaction can be used to explain this type of experience: TAM. Research applying this model shows smooth adoption being based on perceived utility of features and perceived ease of use (Yoo et al., 2012). Further, this research demonstrates that users can adapt to technology in a suboptimalway. For A, this has occurred as the acknowledged benefits of using the seatbelt are dismissed in favor of eliminating negative aspects.

Consistent with this aspect of Ajzen's (1991) model that is used in TAM, users were more likely to be engaged in the process if they felt that they understood it and had been involved from an early stage, 
such as Participant K's nonuse due to confusion about the functional use of her powered chair in her home environment.

As well as the theories discussed earlier, researches from organizational settings and information systems are of relevance here. The Person-environment fit theory by Edwards et al. (2006) is a person's perception of matching to their own environment; also known as "molar." In addition, Klein et al. (2009) also note the confusion of congruence to model and theories in information systems whereby when direct measures are applied to concepts, methodological issues can arise in terms of using the measure. These reasonings can be applied to this context as both Participant $\mathrm{A}$ and $\mathrm{K}$ mismatched the expectation of a feature versus its reality in their own home environments.

This issue could be addressed by clinicians as part of follow-up appointments with questions or a scale designed to identify any unofficial adaptation instigated by the user. An example of a scale that measures reliability, assurance, tangibles, empathy, and responsiveness of a service is SERVQUAL (Parasuraman et al., 1991). The SERVQUAL has been used in many service industries including healthcare (Nyeck et al., 2002). This approach may allow for more systematic testing of users' expectations and could be related to the concepts of barriers/facilitating factors (HBM), expectancyvalues, and perceived behavioral control (TPB) and perceived utility and ease of use (TAM). Thus, clinicians should explore this option using such a scale that could be replicated and applied to a research setting.

\section{Theme 3: The Impact of Other People}

Participants identified that as well as their own expectations, understanding, and priorities, other people could impact their decisions. This occurred in several ways. First, if participants perceived a high degree of utility of their own chair's features, they believed that others would understand and use the features on their chairs too. For example, both Participant $\mathrm{Q}$ and $\mathrm{H}$ acknowledge they cannot represent all wheelchair users and minimize the lack of use of features utilized by other participants.

Participant Q: So I think um, I don't know, I can't speak for everybody who has a wheelchair, but I think that's kind of, um, misunderstanding of a lot of people that there are features that would go to waste because I don't really think they are.

Interviewer: Do you think they [other powered wheelchair users] use all of their functions and features on their wheelchair?

Participant H: Oh, I wouldn't like to say... Obviously some of them are able to get out of their wheelchairs and walk, and some can't, some are permanently in them. With me, I can manage to walk...little walker ones, so I'm not as bad as they are, you know. So, I don't quite know. I should think they probably use all their features because they are unable to walk at all .. I'm assuming they would use everything that's there you know?
Perceptions of consensus are supported within other literature and are associated with risky behaviors. For example, normative misperceptions are associated with excessive drinking (Cunningham et al., 2012). Concepts of subjective norm are presented in the TPB, where individuals' behavioral intentions are predicted by both injunctive norms (e.g., what people think I should do) and descriptive norms (e.g., what most people would do themselves). However, not all participants acted in accordance to these, for example, Participant $\mathrm{D}$ and $\mathrm{K}$ express less certainty and emphasize they are discussing their personal experiences:

Participant D: $\quad$ No, no, that's okay. I was just going to say it's a personal thing really. I mean others might find it more difficult you know? It's just my personal experience of using these particular features I'm confident with.

Interviewer: ... If you're thinking about wheelchair users, do you think that they use their features on their wheelchairs?

Participant K: Um. It depends on how disabled they are, really, isn't it? . . I I have seen people with electric chairs who use all of their features... I've seen some that has it tilted backwards... When I've gone down to the hospital, you know, things like that, I've seen people using them types of chairs ... It's different for each particular person ... So I can't answer for anybody else, really.

Within the TPB, being influenced by descriptive norms implies that a person is aware of what these might be. Without a clear perception of consensus (such as in the case of Participant D), or a clear definition of what this group entails, this could be difficult for wheelchair users to establish. In our study, participants did not see "wheelchair user" as a distinct group. Participants instead seemed to prefer to define ways in which they affiliated to other groups, had other interests or hobbies, or were "more" than their wheelchairs.

Interviewer: Yeah, so what types of online groups do you go on?

Participant O: I mean there's...erm...I'm in a couple of Facebook groups. But that's all to do with music and stuff...I mean there is a [name of health condition] one that I'm in. I suppose chairs sometimes get discussed in there. But again, it's usually like... if you get a new one. What's new on it, or if it breaks what's wrong with it.

Interviewer: Oh okay, so, you're part of [name of health condition group], and is there any other groups or hobbies that you have other than 'gigging'?

Participant D: Um. I mean I try to go swimming on my own accord, things like that. Um. But with regards to 
any sort of support like, no I'm not affiliated with any of that at the moment... One of the biggest things I'm really enjoying, that I do outside of my main works that I'm doing is that I'm a Cosplayer. Have you heard of that at all?

Interviewer: Yeah. Okay. So, um, so you're part of the [name of health condition] group as well?

Participant K: Yeah, part of the [name of health condition] group, yeah.

Interviewer: Are you a part of any other groups you go to?

Participant K: Just the [name of health condition] group.

Interviewer: Are you a part of any online groups?

Participant K: No.

Interviewer: No, no, no online groups. Do you have any hobbies? Do you do anything else?

Participant K: Oh yeah! I've got plenty of hobbies. Um. On a Tuesday I go to ladies club... and then I go to a card making, well, on Friday I start in a card making club. Because I love making cards. Birthday cards, wedding cards.

Interviewer: ...Are you part of any other groups that you attend? So you're a part of [name of disability sport] ...

Participant R: Loads.

Interviewer: Can you name some for me?

Participant R: Well [radio station name] ... I own that one. Um. I'm Trace hosting...I'm part of um Trace Genealogy... I'm also involved in the Royal Navy Association for aircraft handlers...I'm now the [job role]. I'm also the [job role]. I'm also the [other job role]. And I'm also *stifle* the, um, area rep for Wales... That keeps me going and um every weekend is usually a Navy reunion somewhere.

Participant J: ...I've adapted myself to the wheelchair, not the wheelchair has adapted to me.

For those with visible disabilities, especially powered wheelchair users, bodies are the obvious source of an individual's disability; often being associated with incapability and limitations (Blinde \& McClung, 1997; Mayer \& Eisenberg, 1988). Moreover, if a disabled individual identifies themselves with the associative link of being incapable and having limitations in life, a disabled person's self-esteem level and desire to actively be a part of a wheelchair group may be low. This is in accordance with how the social identity theory (SIT) would link a person's identification and self-esteem to group membership (Tajfel et al., 1979). For example, Bogart et al. (2017) distributed a survey to the general public and found in the 710 participants who reported one impairment, stigma, and severity of disability were the strongest predictors of disability identification. Therefore, those with disabilities who are identifying themselves as disabled due to stigmatization may not have applied to our cohort of powered wheelchair users. An example of individuals not identifying as disabled was found in swimmers with various disabilities who noted a strong athletic identity and reported sport as being important to them (Martin et al., 1995).

Other theories explaining why those with disabilities do not identify or like to be identified as disabled are self-determination theory and self-enhancement theory. Self-determination theory "refers to both the right and capacity of individuals to exert control over and direct their lives" (Wehmeyer, 2004, p. 23). Wehmeyer states that disabled individuals who have self-belief in one's capabilities as well as knowledge of their own strengths and limitations will be able to have self-regulated autonomous behavior, selfsufficiency, and self-advocacy (Wehmeyer, 2004, 2005; Wehmeyer \& Abery, 2013). Whereas self-enhancement theory contends that those with negative self-concepts with low self-esteem will try and enhance their self-views by thinking highly of themselves and will want others to treat them in a positive way (Swann et al., 1987). Both theories may explain some of the perceptions held by those in our study sample.

Given the differences between the way our current participants chose to identify themselves, the future research should explore this in more detail by integrating a SIT approach that has been recommended by disability researchers (Dirth \& Branscombe, 2018), and using perhaps a validated scale to measure disability identity, such as the eight-itemDisability Personal Identity Scale (Hahn \& Belt, 2004). This may be useful to examine whether a "powered wheelchair" group identity is beneficial for members.

\section{Conclusion and Implications}

The purpose of this study was to examine literature (see Bragança et al., 2020; Chaves et al., 2007; Schofield et al., 2013; Stinson et al., 2013) and explore wheelchair users' perceptions and usage of assistive technological features on their wheelchairs. The results suggest some implications that may improve the processes surrounding wheelchair prescription, fitting, and advice provided to users.

The current findings suggest that different priorities and levels of understanding existed within participants concerning the emphasis they placed on clinical versus functional benefits. It is not clear from the current study that increasing users' understanding of clinical benefits would lead to adherence. However, simply understanding the functional benefits of the features may lead to a greater degree of usage, but not necessarily in a clinically beneficial way. There may be a juxtaposition between emphasizing the clinical and functional benefits of prescribed features, thus, the future research should investigate this.

Based on the findings of the current research, one potential strategy to improve engagement and use of their features would be for clinicians to give greater emphasis to what a user might consider salient: namely, the functional benefits of a piece of equipment. For example, a tilt in space feature might well be prescribed to address 
postural issues and prevent further deterioration of the user's spine (a clinical benefit) but be perceived by the user as being helpful to make them feel more comfortable (a functional benefit). More explicit linkage between clinical and functional benefits when features are discussed, prescribed, and demonstrated as well as an emphasis on how clinically correct usage from clinicians might help convey the same message in a more user-friendly manner.

\section{Limitations}

There are some potential weaknesses of the study. Although not explicitly assessing "correct usage" and not presenting an intervention to improve adherence, the authors do not know what clinical advice was provided to these users. Moreover, the authors are unaware of the roles that caretakers and family members might have played in the process of a user being prescribed with specific features by only being able to reflect on the experiences of the participants.

Extensions of TAM including variables such as self-identity (Lee et al., 2006) and social and peer influence (Malhotra \& Galletta, 1999; Vahdat et al., 2020) have found that these social factors influence attitude towards technology and acceptance of technology. In addition, TAM2 that incorporates other theoretical constructs to TAM discovered that social influence processes (subjective norm, voluntariness, and image) and cognitive processes (relevance of job, output quality, result demonstrability, and perceived ease of use) influence user's acceptance of technology (Venkatesh \& Davis, 2000). Therefore, it can be argued that many stakeholders (e.g., clinician, peers, and caretakers/family) may be involved in the decision to adopt and accept their assistive technology, thereby making the powered wheelchair user's own TAM processes converge. These TAM2 variables closely align this perspective to the broader barriers and facilitating factors used in the HBM. In addition, the roles of other stakeholders bring in both subjective norms and perceived behavioral control which are key elements of the TPB. Therefore, a model which integrates constructs from all three theories would be useful to further investigate whether the role of other stakeholders and perception of consensus and group identity effects the process of user's engagement and use of assistive technological features on powered wheelchairs.

Users differed in how much they were able to provide in-depth information during interviews due to fatigue and complications with their health conditions. Therefore, we cannot claim that this is a representative of the way that all users engage with their chairs. A potential way to address this is to explore the links between actual usage, reports of usage, and clinical advice; specifically, following users through the process of prescription, adaptation, and use. Once this is established, employing interventions to address adherence in specific circumstances could be useful. Moreover, establishing clear, evidence-based guidelines for the prescription process which consider the perceptions and expectations of users may be of benefit to the user.

\section{Future Research Directions}

In addition to what has been recommended, the future research could investigate the impact of alternative methods of conveying and reinforcing information about the correct ways to use these functions as well as their clinical benefits. Showing and telling, as is the current convention, may not be the most effective strategy. It may also be the case that a "one size fits all" approach is suboptimal. For example, previous research has demonstrated that when teaching younger versus older adults to engage with new technologies, different teaching approaches yield different outcomes for each population (Hickman et al., 2007). An older adult might struggle to take in information due to a decline in working memory capacity or due to perceptions of their own digital literacy skills and as such would need a different approach than a younger participant (Jin et al., 2008). Thus, it is important to consider the strategies that are appropriate and specific to the individual. One possibility for reinforcing this information is the inclusion of tailored feedback through a self-efficacy scale that is temporally proximate to the behavior displayed.

Self-efficacy scales such as the University of Washington Selfefficacy Scale (Amtmann et al., 2012) and the University of Glasgow Social Self-efficacy Scale (Payne \& Jahoda, 2004) have been devised for those with varying disabilities to understand their own disability. In addition, the modified computer selfefficacy scale (Laver et al., 2012) measures the understanding of the use of everyday technology for those with disabilities. However, there is a confidence scale that measures self-efficacy specifically tailored to wheelchair users examining their understanding of their assistive technology. This is the Wheelchair Use Confidence Scale for manual wheelchair users (WheelCon-M; Rushton et al., 2011).

The WheelCon-M is a $0 \%-100 \%$ confidence rating scale for manual wheelchair users with low confidence in operating their chairs. It consists of 62 items across six conceptual areas including: negotiating the physical environment; activities performed in the wheelchair; knowledge and problem solving; advocacy; managing social situations; and managing emotions. All percentages are added and then divided by the number of questions. A version for powered wheelchairs (WheelCon-P) with the refinement to 59 items across the six conceptual areas was created and validated after our study had taken place (Rushton et al., 2017, 2018). In terms of the WheelCon-P, it can be administered by a clinician or via the powered wheelchair user themselves. Most recently, it was used as a measurement of self-efficacy in children (4-17 years old) who are powered wheelchair users that undertook a peer-led training programcalled Seating-To-Go (Wilson et al., 2020). The researchers found that although skills were learnt through the Seating-To-Go program, confidence levels did not increase in children. However, the researchers speculate that there may be confusion to the comprehension of the word "confidence" and how it is interpreted to young age groups. Therefore, using the WheelCon-P in adults may be beneficial to research; subject to the necessary registrations to obtain the scale (Miller, 2020).

Administering the WheelCon-P scale continually would allow a user to obtain information about the utility of his/her behavior, messages about positive benefits of continued engagement, and suggestions for behavioral tweaks that might improve the future clinical or functional experience. If these were delivered as close to the behavior as possible, this would enable the user to form associations between the behavior and the outcome that would serve as a valuable message for continued engagement to prescribed assistive technological powered wheelchair features.

Finally, there appears to be a distinct lack of psychological evidence underpinning practice in the area. Engagement with and 
understanding chair features appears to be an area that is psychological in nature. Therefore, further research could investigate the psychological barriers and facilitators in terms of adherence, engagement, and the use of assistive technology through a mixed method study design involving HBM, TAM, and TPB throughout the wheelchair lifecycle process: namely, through assessment, prescription, and monitoring. We believe that a deeper understanding of the implications of these psychological factors could be beneficial to occupational therapy practice as well as user outcomes.

\section{References}

Ajzen, I. (1991). The theory of planned behavior. Organizational Behavior and Human Decision Processes, 50(2), 179-211. https://doi.org/10.1016/ 0749-5978(91)90020-T

Amtmann, D., Bamer, A. M., Cook, K. F., Askew, R. L., Noonan, V. K., \& Brockway, J. A. (2012). University of Washington self-efficacy scale: A new self-efficacy scale for people with disabilities. Archives of Physical Medicine and Rehabilitation, 93(10), 1757-1765. https://doi.org/10.1016/ j.apmr.2012.05.001

Anderson, D. M., Wozencroft, A., \& Bedini, L. A. (2008). Adolescent girls' involvement in disability sport: A comparison of social support mechanisms. Journal of Leisure Research, 40(2), 183-207. https://doi.org/10 $.1080 / 00222216.2008 .11950137$

Bandura, A., \& Adams, N. E. (1977). Analysis of self-efficacy theory of behavioral change. Cognitive Therapy and Research, 1(4), 287-310. https://doi.org/10.1007/BF01663995

Barsalou, L. W. (2008). Grounded cognition. Annual Review of Psychology, 59, 617-645. https://doi.org/10.1146/annurev.psych.59.103006.093639

Barsalou, L. W., Niedenthal, P. M., Barbey, A. K., \& Ruppert, J. A. (2003). Social embodiment. Psychology of Learning and Motivation, 43, 43-92. https://doi.org/10.1016/S0079-7421(03)01011-9

Black, J. B. (2010). An embodied/grounded cognition perspective on educational technology. In Khine M., Saleh I. (Eds.) New Science of Learning (pp. 45-52). Springer. https://doi.org/10.1007/978-1-44195716-0_3

Blinde, E. M., \& McClung, L. R. (1997). Enhancing the physical and social self through recreational activity: Accounts of individuals with physical disabilities. Adapted Physical Activity Quarterly, 14(4), 327-344. https:// doi.org/10.1123/apaq.14.4.327

Bogart, K. R., Rottenstein, A., Lund, E. M., \& Bouchard, L. (2017). Who self-identifies as disabled? An examination of impairment and contextual predictors. Rehabilitation Psychology, 62(4), 553-562. https://doi.org/ 10.1037/rep0000132

Bragança, S., Castellucci, I., Costa, E., Arezes, P., \& Carvalho, M. (2020). Anthropometric data for wheelchair users: A systematic literature review. International Journal of Occupational Safety and Ergonomics, 26(1), 149-172. https://doi.org/10.1080/10803548.2019.1567974

Braun, V., \& Clarke, V. (2006). Using thematic analysis in psychology. Qualitative Research in Psychology, 3(2), 77-101. https://doi.org/10 .1191/1478088706qp063oa

Carrington, P., Chang, K., Mentis, H., \& Hurst, A. (2015, October). But, I don't take steps: Examining the inaccessibility of fitness trackers for wheelchair athletes. Proceedings of the 17th International ACM SIGACCESS Conference on Computers \& Accessibility (pp. 193-201). ACM. https://doi.org/10.1145/2700648.2809845

Carrington, P., Laput, G., \& Bigham, J. P. (2018, October). Exploring the data tracking and sharing preferences of wheelchair athletes. Proceedings of the 20th International ACM SIGACCESS Conference on Computers and Accessibility (pp. 242-248). ACM. https://doi.org/10.1145/3234695 .3236353

Carvalho, T., Alvarez, M. J., Barz, M., \& Schwarzer, R. (2015). Preparatory behavior for condom use among heterosexual young men: A longitudinal mediation model. Health Education \& Behavior, 42(1), 92-99. https:// doi.org/10.1177/1090198114537066

Chaves, E. S., Cooper, R. A., Collins, D. M., Karmarkar, A., \& Cooper, R. (2007). Review of the use of physical restraints and lap belts with wheelchair users. Assistive Technology, 19(2), 94-107. https://doi.org/ 10.1080/10400435.2007.10131868

Clark, A. (2007). Re-inventing ourselves: The plasticity of embodiment, sensing, and mind. The Journal of Medicine and Philosophy, 32(3), 263-282. https://doi.org/10.1080/03605310701397024

Cunningham, J. A., Neighbors, C., Wild, T. C., \& Humphreys, K. (2012). Normative misperceptions about alcohol use in a general population sample of problem drinkers from a large metropolitan city. Alcohol and Alcoholism, 47(1), 63-66. https://doi.org/10.1093/alcalc/agr125

Devi, S., Goyal, S., \& Ravindra, S. (2013). Evaluation of environmental barriers faced by wheelchair users in India. Disability, CBR and Inclusive Development, 24(3), 61-74. https://doi.org/10.5463/dcid.v24i3.209

Ding, D., Leister, E., Cooper, R. A., Cooper, R., Kelleher, A., Fitzgerald, S. G., \& Boninger, M. L. (2008). Usage of tilt-in-space, recline, and elevation seating functions in natural environment of wheelchair users. Journal of Rehabilitation Research and Development, 45(7), 973-984. https://doi.org/10.1682/JRRD.2007.11.0178

Dirth, T. P., \& Branscombe, N. R. (2018). The social identity approach to disability: Bridging disability studies and psychological science. Psychological Bulletin, 144(12), 1300-1324. https://doi.org/10.1037/bul0000156

Dourish, P. (2004). Where the action is: The foundations of embodied interaction. MIT press.

Dumpit, D., \& Fernandez, Z. (2017). Analysis of the use of social media in Higher Education Institutions (HEIs) using the Technology Acceptance Model. International Journal of Educational Technology in Higher Education, 14, Article 5. https://doi.org/10.1186/s41239-017-0045-2

Edwards, J. R., Cable, D. M., Williamson, I. O., Lambert, L. S., \& Shipp, A. J. (2006). The phenomenology of fit: Linking the person and environment to the subjective experience of person-environment fit. Journal of Applied Psychology, 91(4), 802-827. https://doi.org/10.1037/0021-9010.91.4.802

Fliess-Douer, O., Vanlandewijck, Y. C., \& Van der Woude, L. H. V. (2013). Reliability and validity of perceived self-efficacy in wheeled mobility scale among elite wheelchair-dependent athletes with a spinal cord injury. Disability and Rehabilitation: An International, Multidisciplinary Journal, 35(10), 851-859. https://doi.org/10.3109/09638288.2012 .712198

GOV.UK. (2019). National wheelchair data collection for quarter 1 2019/20 [website]. https://www.gov.uk/government/statistics/national-wheelchairdata-collection-for-quarter-1-201920

Greenwood, C. M., Dzewaltowski, D. A., \& French, R. (1990). Self-efficacy and psychological well-being of wheelchair tennis participants and wheelchair nontennis participants. Adapted Physical Activity Quarterly, 7(1), 12-21. https://doi.org/10.1123/apaq.7.1.12

Hahn, H. D., \& Belt, T. L. (2004). Disability identity and attitudes toward cure in a sample of disabled activists. Journal of Health and Social Behavior, 45(4), 453-464. https://doi.org/10.1177/002214650404500407

Heath, C., \& Luff, P. (2000). Technology in action. Cambridge University Press. https://doi.org/10.1017/CBO9780511489839

Heath, C., Luff, P., \& Svensson, M. S. (2003). Technology and medical practice. Sociology of Health \& Illness, 25(3), 75-96. https://doi.org/10 $.1111 / 1467-9566.00341$

Helander, M. G. (2003). Forget about ergonomics in chair design? Focus on aesthetics and comfort! Ergonomics, 46(13-14), 1306-1319. https:// doi.org/10.1080/00140130310001610847

Hickman, J. M., Rogers, W. A., \& Fisk, A. D. (2007). Training older adults to use new technology. The Journals of Gerontology Series B, Psychological Sciences and the Social Sciences, 62(SI 1), 77-84.https://doi.org/10.1093/ geronb/62.special_issue_1.77

Information Commissioner's Office. (2018). Guide to data protection. https://ico.org.uk/for-organisations/guide-to-data-protection/ 
Jan, Y. K., Jones, M. A., Rabadi, M. H., Foreman, R. D., \& Thiessen, A. (2010). Effect of wheelchair tilt-in-space and recline angles on skin perfusion over the Ischial tuberosity in people with spinal cord injury. Archives of Physical Medicine and Rehabilitation, 91(11), 1758-1764. https://doi.org/10.1016/j.apmr.2010.07.227

Jin, J., Sklar, G. E., Min Sen Oh, V., \& Li, C. S. (2008). Factors affecting therapeutic compliance: A review from the patient's perspective. Therapeutics and Clinical Risk Management, 4(1), 269-286. https:// doi.org/10.2147/TCRM.S1458

Johnson, J., \& Rowlands, T. (2012). The interpersonal dynamics of in-depth interviewing. In J. F. Gubrium, J. A. Holstein, A. B. Marvasti, \& K. D. McKinney (Eds.), The SAGE handbook of interview research: The complexity of the craft (pp. 99-114). Sage Publications. https://doi.org/ $10.4135 / 9781452218403$

Klein, G., Jiang, J. J., \& Cheney, P. (2009). Resolving difference score issues in information systems research. Management Information Systems Quarterly, 33, 811-826. https://doi.org/10.2307/20650328

Lancioni, G., O'reilly, M., Singh, N., Sigafoos, J., Oliva, D., Smaldone, A., La Martire, M., Navarro, J., Spica, A., \& Chirico, M. (2011). Technologyassisted programs for promoting leisure or communication engagement in two persons with pervasive motor or multiple disabilities. Disability and Rehabilitation: Assistive Technology, 6(2), 108-114. https://doi.org/10 .3109/17483107.2010.496524

Lancioni, G. E., Singh, N. N., O'Reilly, M. F., Sigafoos, J., Boccasini, A., Perilli, V., \& Spagnuolo, C. (2017). Persons with multiple disabilities manage positive leisure and communication engagement through a technology-aided program. International Journal of Developmental Disabilities, 63(3), 148-157. https://doi.org/10.1080/20473869.2016.1187462

Lancioni, G. E., Singh, N. N., O'Reilly, M. F., Sigafoos, J., Oliva, D., Signorino, M., \& De Tommaso, M. (2010). Helping a man with acquired brain injury and multiple disabilities manage television use via assistive technology. Clinical Case Studies, 9(4), 285-293. https://doi.org/10.1177/ 1534650110378036

Laver, K., George, S., Ratcliffe, J., \& Crotty, M. (2012). Measuring technology self efficacy: Reliability and construct validity of a modified computer self efficacy scale in a clinical rehabilitation setting. Disability and Rehabilitation: An International, Multidisciplinary Journal, 34(3), 220-227. https://doi.org/10.3109/09638288.2011.593682

Lavie, N. (2010). Attention, distraction, and cognitive control under load. Current Directions in Psychological Science, 19(3), 143-148. https:// doi.org/10.1177/0963721410370295

Ledgerwood, A., Eastwick, P. W., \& Smith, L. K. (2018). Toward an integrative framework for studying human evaluation: Attitudes toward objects and attributes. Personality and Social Psychology Review, 22(4), 378-398. https://doi.org/10.1177/1088868318790718

Lee, Y., Lee, J., \& Lee, Z. (2006). Social influence on technology acceptance behavior: Self-identity theory perspective. ACM SIGMIS Database: The DATABASE for Advances in Information Systems, 37(2-3), 60-75. https:// doi.org/10.1145/1161345.1161355

Lin, H.-F. (2011). An empirical investigation of mobile banking adoption: The effect of innovation attributes and knowledge-based trust. International Journal of Information Management, 31(3), 252-260. https://doi.org/10.1016/j.ijinfomgt.2010.07.006

Lunney, A., Cunningham, N. R., \& Eastin, M. S. (2016). Wearable fitness technology: A structural investigation into acceptance and perceived fitness outcomes. Computers in Human Behavior, 65, 114-129. https:// doi.org/10.1016/j.chb.2016.08.007

Malhotra, Y., \& Galletta, D. F. (1999). Extending the technology acceptance model to account for social influence: Theoretical bases and empirical validation [Conference session]. Proceedings of the 32nd Annual Hawaii International Conference on Systems Sciences. HICSS-32. Abstracts and CD-ROM of Full Papers, Maui, HI, USA. https://doi.org/10.1109/HICSS .1999 .772658
Martin, J. J. (2002). Training and performance self-efficacy, affect, and performance in wheelchair road racers. The Sport Psychologist, 16(4), 384-395. https://doi.org/10.1123/tsp.16.4.384

Martin, J. J. (2008). Multidimensional self-efficacy and affect in wheelchair basketball players. Adapted Physical Activity Quarterly, 25(4), 275-288. https://doi.org/10.1123/apaq.25.4.275

Martin, J. J., Adams-Mushett, C., \& Smith, K. L. (1995). Athletic identity and sport orientation of adolescent swimmers with disabilities. Adapted Physical Activity Quarterly, 12(2), 113-123. https://doi.org/10.1123/apaq 12.2 .113

Martin, J. J., \& Mushett, C. A. (1996). Social support mechanisms among athletes with disabilities. Adapted Physical Activity Quarterly, 13(1), 74-83. https://doi.org/10.1123/apaq.13.1.74

Mayer, J. D., \& Eisenberg, M. G. (1988). Mental representation of the body: Stability and change in response to illness and disability. Rehabilitation Psychology, 33(3), 155-171. https://doi.org/10.1037/h0091692

Miller, W. C. (2020). Wheelchair user confidence scale (WheelCon). http:// millerresearch.osot.ubc.ca/tools/mobility-outcome-tools-2/wheelchair-useconfidence-scale-wheelcon/

Money, A. G., Atwal, A., Young, K. L., Day, Y., Wilson, L., \& Money, K. G. (2015). Using the Technology Acceptance Model to explore community dwelling older adults' perceptions of a 3D interior design application to facilitate pre-discharge home adaptations. BMC Medical Informatics and Decision Making, 15(1), Article 73. https://doi.org/10.1186/s12911-0150190-2

NHS Executive. (1996). Health service guidelines for the indoor-outdoor powered wheelchair scheme. HSG (96) 34. Department of Health.

Nyeck, S., Morales, M., Ladhari, R., \& Pons, F. (2002). 10 years of service quality measurement: Reviewing the use of the SERVQUAL instrument. The Bi-Annual Academic Publication of Universidad ESAN, 7(13), $101-107$.

O'Regan, J. K., \& Noë, A. (2001). A sensorimotor account of vision and visual consciousness. Behavioral and Brain Sciences, 24(5), 939-973. https://doi.org/10.1017/S0140525X01000115

Office of Population Censuses and Surveys. Social Survey Division. (1989). Survey of disabled adults in private households, 1985 [data collection] UK Data Service. Accessed online February 9, 2018, from https://doi.org/ 10.5255/UKDA-SN-2577-1

Open Science Framework. (2020). User perceptions of power chair features, 2020 [data collection]. UK Data Service. Accessed online April 24, 2020, from https://osf.io/3s7nb/

Papworth Trust. (2018). Facts and figures 2018: Disability in the United Kingdom. https://www.papworthtrust.org.uk/about-us/publications/ papworth-trust-disability-facts-and-figures-2018.pdf

Parasuraman, A., Berry, L. L., \& Zeithaml, V. A. (1991). Refinement and reassessment of the SERVQUAL scale. Journal of Retailing, 67(4), $420-451$.

Park, E., Kim, K. J., \& Kwon, S. J. (2016). Understanding the emergence of wearable devices as next-generation tools for health communication. Information Technology \& People, 29(4), 717-732. https://doi.org/10 .1108/ITP-04-2015-0096

Payne, R., \& Jahoda, A. (2004). The Glasgow Social Self-Efficacy Scale-A new scale for measuring social self-efficacy in people with intellectual disability. Clinical Psychology \& Psychotherapy, 11(4), 265-274. https:// doi.org/10.1002/cpp.412

Ripat, J. D., Brown, C. L., \& Ethans, K. D. (2015). Barriers to wheelchair use in the winter. Archives of Physical Medicine and Rehabilitation, 96(6), 1117-1122. https://doi.org/10.1016/j.apmr.2015.01.020

Rosenstock, I. M. (1974). Historical origins of the health belief model. Health Education Monographs, 2, 328-335. https://doi.org/10.1177/ 109019817400200403

Rushton, P. W., Miller, W. C., Lee Kirby, R., Eng, J. J., \& Yip, J. (2011). Development and content validation of the wheelchair use confidence 
scale: A mixed-methods study. Disability and Rehabilitation: Assistive Technology, 6(1), 57-66. https://doi.org/10.3109/17483107.2010.512970 Rushton, P. W., Routhier, F., \& Miller, W. C. (2018). Measurement properties of the WheelCon for powered wheelchair users. Disability and Rehabilitation: Assistive Technology, 13(7), 614-619. https://doi.org/ 10.1080/17483107.2017.1358301

Rushton, P. W., Smith, E., Miller, W. C., \& Vaughan, K. (2017). Measuring wheelchair confidence among power wheelchair users: An adaptation of the WheelCon-M using focus groups and a think aloud process. Disability and Rehabilitation: Assistive Technology, 12(1), 39-46. https://doi.org/10 .3109/17483107.2015.1063018

Sakakibara, B. M., Miller, W. C., Eng, J. J., Routhier, F., \& Backman, C. L. (2015). Health, personal, and environmental predictors of wheelchair-use confidence in adult wheelchair users. Physical Therapy, 95(10), 13651373. https://doi.org/10.2522/ptj.20140537

Sanchez, C. A., \& Alley, Z. M. (2016). Advertising effectiveness and attitude change vary as a function of working memory capacity. Applied Cognitive Psychology, 30(6), 1093-1099. https://doi.org/10.1002/acp.3290

Schofield, R., Porter-Armstrong, A., \& Stinson, M. (2013). Reviewing the literature on the effectiveness of pressure relieving movements. Nursing Research and Practice, 2013. Article 124095. https://doi.org/ $10.1155 / 2013 / 124095$

Schrope, M. (2001, June 2). Simply sensational. New Scientist, pp. 30-33 Sheeran, P., Klein, W. M. P., \& Rothman, A. J. (2017). Health behavior change: Moving from observation to intervention. Annual Review of Psychology, 68, 573-600. https://doi.org/10.1146/annurev-psych010416-044007

Shenton, A. K. (2004). Strategies for ensuring trustworthiness in qualitative research projects. Education for Information, 22(2), 63-75. https:// doi.org/10.3233/EFI-2004-22201

Sigafoos, J., van der Meer, L., Schlosser, R. W., Lancioni, G. E., O'Reilly, M. F., \& Green, V. A. (2016). Augmentative and Alternative Communication (AAC) in intellectual and developmental disabilities. In J. K. Luiselli \& A. J. Fischer (Eds.), Computer-assisted and web-based innovations in psychology, special education, and health (pp. 255-285). Academic Press.

Smith, L. B. (2005). Cognition as a dynamic system: Principles from embodiment. Developmental Review, 25(3-4), 278-298. https://doi.org/ 10.1016/j.dr.2005.11.001

Smith, M. J., \& Salvendy, G. (Eds.). (2001). Systems, social, and internationalization design aspects of human-computer interaction (Vol. 2). CRC Press.

Stasolla, F., \& De Pace, C. (2014). Assistive technology to promote leisure and constructive engagement by two boys emerged from a minimal conscious state. NeuroRehabilitation, 35(2), 253-259. https://doi.org/10 .3233/NRE-141112

Stasolla, F., Perilli, V., \& Boccasini, A. (2016). Assistive technologies for persons with severe-profound intellectual and developmental disabilities. In J. K. Luiselli \& A. J. Fischer (Eds.), Computer-assisted and web-based innovations in psychology, special education, and health (pp. 287-310). Academic Press. https://doi.org/10.1016/B978-0-12802075-3.00011-5

Stinson, M., Gillan, C., \& Porter-Armstrong, A. (2013). A literature review of pressure ulcer prevention: Weight shift activity, cost of pressure care and role of the occupational therapist. British Journal of
Occupational Therapy, 76(4), 169-178. https://doi.org/10.4276/ 030802213 X13651610908371

Stockton, L., \& Parker, D. (2002). Pressure relief behaviour and the prevention of pressure ulcers in wheelchair users in the community. Journal of Tissue Viability, 12(3), 84-99. https://doi.org/10.1016/ S0965-206X(02)80031-6

Suchman, L., \& Suchman, L. A. (2007). Human-machine reconfigurations: Plans and situated actions. Cambridge University Press.

Swann, W. B., Griffin, J. J., Predmore, S. C., \& Gaines, B. (1987). The cognitive-affective crossfire: When self-consistency confronts selfenhancement. Journal of Personality and Social Psychology, 52(5), 881-889. https://doi.org/10.1037/0022-3514.52.5.881

Tajfel, H., \& Turner, J. C. (1979). An integrative theory of intergroup conflict. In W. G. Austin \& S. Worchel (Eds.), The Social Psychology of Intergroup Relations (pp. 33-47). Brooks/Cole.

Tong, A., Sainsbury, P., \& Craig, A. (2007). Consolidated criteria for reporting qualitative research (COREQ): A 32-item checklist for interviews and focus groups. International Journal for Quality in Health Care, 19(6), 349-357. https://doi.org/10.1093/intqhe/mzm042

Vahdat, A., Alizadeh, A., Quach, S., \& Hamelin, N. (2020, in press). Would you like to shop via mobile app technology? The technology acceptance model, social factors and purchase intention. Australasian Marketing Journal. Advance online publication. https://doi.org/10.1016/j.ausmj .2020 .01 .002

van der Heide, I., Heijmans, M., Schuit, A. J., Uiters, E., \& Rademakers, J. (2015). Functional, interactive and critical health literacy: Varying relationships with control over care and number of GP visits. Patient Education and Counseling, 98(8), 998-1004. https://doi.org/10.1016/j .pec.2015.04.006

Varela, F. J., Thompson, E., \& Rosch, E. (2016). The embodied mind: Cognitive science and human experience. MIT press.

Venkatesh, V., \& Davis, F. D. (2000). A theoretical extension of the technology acceptance model: Four longitudinal field studies. Management Science, 46(2), 186-204. https://doi.org/10.1287/mnsc.46.2.186.11926

Wehmeyer, M. L. (2004). Self-determination and the empowerment of people with disabilities. American Rehabilitation, 28, 22-29.

Wehmeyer, M. L. (2005). Self-determination and individuals with severe disabilities: Re-examining meanings and misinterpretations. Research and Practice for Persons with Severe Disabilities, 30(3), 113-120. https:// doi.org/10.2511/rpsd.30.3.113

Wehmeyer, M. L., \& Abery, B. H. (2013). Self-determination and choice. Intellectual and Developmental Disabilities, 51(5), 399-411. https:// doi.org/10.1352/1934-9556-51.5.399

Wilburn, J., Twiss, J., Kemp, K., \& McKenna, S. P. (2017). A qualitative study of the impact of Crohn's disease from a patient's perspective. Frontline Gastroenterology, 8(1), 68-73. https://doi.org/10.1136/ flgastro-2015-100678

Wilson, D., Best, K., \& Miller, W. (2020). 3v: Peer-led approaches for improving satisfaction with participation, wheelchair skills and selfefficacy among children who use manual and power wheelchairs [Symposium]. Syllabus, 129-130.

Yoo, S. J., Han, S., \& Huang, W. (2012). The roles of intrinsic motivators and extrinsic motivators in promoting e-learning in the workplace: A case from South Korea. Computers in Human Behavior, 28(3), 942-950. https:// doi.org/10.1016/j.chb.2011.12.015 


\section{Appendix}

Table A1

Clinical Assistive Technology Powered Wheelchair $(P W)$ Features With Percentage of Participant Prescribed Said Feature and Percentage of Use

Participant $\quad$ Features of powered wheelchair

Percentage of participants

Pressure cushion

Tilt in space

Elevating leg rests

Recline

Headrest

Curb climber

Pelvic belt

Riser

Chest harness; lynx backrest; heel loops

Foot/ankle straps

Lateral thoracic supports

Hip guides

Knee block

Shoulder harness

Pommel

Due to have tilt and elevating leg rests on new PW
Percentage of participants that used the feature

$\begin{array}{cc}86.67 & 76.92 \\ 53.33 & 75 \\ 46.67 & 100 \\ 73.33 & 54.55 \\ 73.33 & 63.64 \\ 33.33 & 60 \\ 66.67 & 50 \\ 13.33 & 100 \\ 6.67 & 100 \\ 26.67 & 75 \\ 40 & 66.67 \\ 13.33 & 100 \\ 20 & 100 \\ 6.67 & 100 \\ 20 & 66.67 \\ \text { N/A } & \text { N/A }\end{array}$

Received April 30, 2020

Revision received July 27, 2020

Accepted July 27, 2020 